\title{
Clinical Experts Statement: The Definition, Prescription, and Application of Cupping Therapy
}

\author{
S. Andrew Cage, MEd, LAT, ATC1,2; Diana M. Gallegos, MS, LAT, ATC ${ }^{1}$; Brian Coulombe, DAT, LAT, ATC ${ }^{4}$; \\ Brandon J Warner, MEd, LAT, ATC2,3 \\ 1The University of Texas at Tyler, 2 University of North Carolina Greensboro, Kinesiology, ${ }^{3}$ Grand Canyon University, ${ }^{4}$ Texas \\ Lutheran University
}

Key Phrases

College and university patient population, therapeutic devices, manual techniques, cupping therapy

\begin{abstract}
Author Characteristics
The first author, Andrew S. Cage, has obtained his International Cupping Therapy Therapist certification and is a member of the International Cupping Therapy Association. Mr. Cage also has several peer-reviewed publications as well as international, national, regional, and local presentations on the use of cupping therapy in sports medicine and rehabilitation. Mr. Cage has presented numerous times on evidence based approaches on the use of cupping therapy and uses cupping therapy extensively in his clinical practice. Further, Brandon Warner and Diana Gallegos, have also received certifications in cupping therapy and myofascial decompression and use cupping therapy in their clinical practice regularly. Both Mr. Warner and Ms. Gallegos have several peer-reviewed publications and presentations at the national, regional, and local levels.
\end{abstract}

\section{Correspondence}

S. Andrew Cage, The University of Texas Tyler, 11325 Preakness Dr., Flint, TX 75762.

E-mail: sacage@uncg.edu

\section{Full Citation}

Cage SA, Gallegos DM, Coulombe B, \& Warner BJ. Clinical experts statement: The definition, prescription, and application of dry cupping therapy. Clin Pract Athl Train. 2019;2(2): 4-1 1 https://doi.org/10.31622/2019/0002.2.

Submitted: May 29, 2019 Accepted: June 6, 2019

\section{INTRODUCTION}

Cupping therapy is an ancient modality the use of which has been documented as early as 3300 BC. ' In the past two decades, dry cupping therapy has grown in popularity in the United States and other countries where Western Medicine is the primary source of healthcare. ${ }^{1}$ A large amount of this popularity can be attributed to increased media interest resulting from elite level athletes receiving cupping therapy. ${ }^{2,3}$ Even though cupping therapy has gained popularity as a treatment device in the United States, there is still no consensus on the ideal parameters for applying a cupping therapy treatment to patients competing in amateur or professional athletics. ${ }^{1}$ The lack of consensus related to this medical issue can be attributed at least in part to a lack of high quality studies, lack of randomized controlled trials involving subjects participating in organized athletics, and a lack of standardized methodology. $1,4,5$

Within the medical and healthcare field, various methods of creating consensus statements on best practices are commonly used and accepted.6-9 These techniques have been used to publish consensus statements in areas including respiratory, urologic, and geriatric medicine. ${ }^{6-9}$ In instances in which there are deficiencies or contradictions within the current literature, the Delphi technique is one method of determining consensus that can be employed. ${ }^{6}$ Therefore, the purpose of this clinical expertise commentary was to use the Delphi technique to develop a clinical expertise statement on the definition and description of cupping therapy, as well as the prescription and application of dry cupping therapy when providing athletic training services. This statement was to be created with the intent of serving as a guide for clinicians until gaps in literature could be addressed.

\section{METHODS}

A review of the available literature was conducted using PubMed and GoogleScholar to locate published materials that could contribute to an initial list of statements to utilize in the Delphi process. The review focused on: description and definition of cupping therapy, prescription of 
cupping therapy, and application of cupping therapy. The literature search looked for English language studies that had been published after 2013. Ultimately, 31 sources were utilized in the creation of the literature review. ${ }^{1-5,10-35}$

Upon completion of the review of literature, a panel of 10 athletic trainers who held a postprofessional credential in cupping therapy were invited to participate in a series of online surveys and forums. Demographic information for the panel of experts can be found in Table 1.

Table 1. Panel demographic information

\begin{tabular}{ll}
\hline Sex & $\begin{array}{l}\text { Male }(\mathrm{N}=5), \\
\text { Female }(\mathrm{N}=5)\end{array}$ \\
Age (Years) & $31.3 \pm 5.01$ \\
$\begin{array}{l}\text { Certified Athletic Training } \\
\text { Experience (Years) }\end{array}$ & $7.0 \pm 3.71$ \\
$\begin{array}{l}\text { Patients Treated Weekly } \\
\text { with Cupping Therapy }\end{array}$ & $9.1 \pm 4.01$ \\
\hline $\begin{array}{l}\text { Age, Experience, and Patients Treated } \\
\text { presented as means with SD. }\end{array}$
\end{tabular}

After collecting demographic information from the panelists, the Delphi technique was utilized in a similar manner to that which was performed by Maher et al. ${ }^{6}$ Panelists with a history of regularly performing formally trained cupping therapy as part of their daily athletic training practice were identified by the primary investigator and independently recruited to participate. Panelists received an electronic copy of the literature review, and were asked to review it for one week. Panelists were then surveyed on a series of statements regarding the definition and description, prescription, and application of cupping therapy on their patient population. Panelists were asked to rate each statement based off of whether or not they felt it warranted inclusion in the overarching clinical expertise statement ( 1 = Definitely do NOT include to $9=$ Definitely include). Using the protocol outlined in Table 2, all statements were analyzed by the primary investigator to determine if they warranted inclusion, exclusion or modification. Following the first round, panelists received a web-based spreadsheet that outlined the results

Copyright (C) Indiana State University

ISSN Online 2577-8188 of the first survey. The spreadsheet also included areas for panelists to comment on what they felt should be modified in the statements that had not qualified for inclusion in order for them to be included in the final clinical expertise statement. After modifications were made to the remaining statements, the second survey was sent to the panelists asking them to re-rate the revised statements. Upon completing the second round of surveying, consensus was reached on all included statements based off each included statement having a median rating of 8 or higher.

Table 2. Statement inclusion key

\begin{tabular}{|c|c|}
\hline $\begin{array}{c}\text { Statement } \\
\text { Result }\end{array}$ & Threshold Applied \\
\hline $\begin{array}{l}\text { Definitely } \\
\text { Include }\end{array}$ & $\begin{array}{l}\text { 1. } \geq 80 \% \text { of panel rated } \\
\text { statement }=9 \\
\text { 2. Median rating of } \geq 8\end{array}$ \\
\hline $\begin{array}{l}\text { Maybe } \\
\text { Include }\end{array}$ & $\begin{array}{l}\text { 1. } \geq 70 \% \text { of panel rated } \\
\text { statement }=9 \\
\text { 2. Medial rating of } \geq 7\end{array}$ \\
\hline $\begin{array}{l}\text { Definitely } \\
\text { exclude }\end{array}$ & $\begin{array}{l}\text { 1. } \leq 80 \% \text { of panel rated } \\
\text { statement }=1 \\
\text { 2. Median rating of } \leq 2\end{array}$ \\
\hline Review & $\begin{array}{l}\text { 1. Major revisions } \\
\text { suggested by panelist. } \\
\text { 2. }<70 \% \text { of panel rated } \\
\text { statement }=9\end{array}$ \\
\hline
\end{tabular}

\section{RESULTS}

Following the review of literature, 67 statements were developed. These statements addressed the definition and description of cupping therapy, prescription of cupping therapy (specifically, indications and contraindications), and the application of cupping therapy. All 10 panelists participated in the demographics survey, as well as the first and second round of rating statements. Seven out of 10 panelists provided comments and suggested revisions for the statements that did not warrant inclusion or exclusion after the first round of rating. Additionally, five panelists were contacted in a one-on-one fashion to request clarification on comments or to provide clarifications on the investigator's remarks. 
After the rating of the original 67 statements was completed, 31 statements remained unmodified, four were excluded, and 32 were presented to the panel for revisions. A total of six of the statements regarding the description and definition of cupping therapy were combined into a single statement. Additionally, a single statement was created regarding mediums from five statements following agreement on oils were the preferable mediums to lotions. Statements regarding the number of pumps to use with plastic cups on experienced and inexperienced patients were combined into two respective statements. Additionally, the statement regarding the use of cupping therapy on the appendages of a pregnant patient was modified to include physician consent as a necessity.

Of the remaining 30 statements from the first round of rating, eight modified statements were reviewed and rated in the second round. During this round of rating, all eight were unmodified and included in the final overarching statement. As all remaining statements had reached a consensus, it was concluded that there was no need to undergo a second round of revisions and ratings. Thus, the final 39 statements are presented in Table 3, Table 4, and Table 5 as the panel's clinical expert statement on the description, prescription, and application of cupping therapy in athletic training.

\section{DISCUSSION}

The purpose of this study was to develop a clinical statement on the description and definition, prescription, and application of cupping therapy in athletic training. The literature review results in 67 initial statements. Following 2 rounds of rating, 39 statements were included in the final clinical expert statements. Ultimately, the goal of this consensus clinical expert statement was to attempt to reach a level of agreement based off of expert opinion in the absence of high-quality evidence. This method was chosen based off the success of using it in other healthcare professions to create consensus statements for conditions and interventions that did not have clearly set guidelines. ${ }^{6}$ The Delphi technique has been used by other authors to reach consensus statements on a variety of medical conditions. ${ }^{6-9}$ Maher $^{6}$ noted this technique had exceptional utility when used for establishing guidelines for conditions that were not well documented in research-based literature.

Upon completion of the first round of review, revisions were made to the statements that qualified for modification based off of input from the panelists. Revisions were made to condense and clarify the description and definition of cupping therapy, the use of cupping therapy on the appendages of pregnant patients, the amount of suction used on patients with and without experience with cupping therapy, and the types of mediums used for applying cupping therapy. These statements are intended to serve as a tool for athletic trainers looking to incorporate cupping therapy into their clinical practice. Through review of these statements, athletic trainers may be able to practice cupping therapy with the knowledge that these aspects of the practice have been reviewed by a clinician-driven panel.

The authors encourage all athletic trainers and allied healthcare practitioners looking to practice cupping therapy to carefully review and consider each of these statements. The information contained within these statements is not inclusive of all individual scenarios and circumstances. Extenuating variables such as patient health, state and federal regulations, cultural beliefs, and patient values may affect the ability of a clinician to implement these statements into their practice. The authors strongly encourage individuals to seek out formal education and training in cupping therapy prior to administering treatments to patients. The statements contained within this document should be viewed as a resource and not a rigid set of guidelines for practicing cupping therapy. 
Table 3. Agreed Upon Definition of Cupping Therapy 1,4,5,12,17,21

\section{Cupping Therapy Description/Definition}

1. Cupping therapy utilizes suction from one of a variety of methods.

2. Cups used for cupping therapy can be made of materials including plastic, glass, rubber, silicone, and wood.

3. Some methods of creating suction on the tissue being treated include: pumping air from a plastic cup, creating an oxygen deficit in a glass cup with an open flame, and manually manipulating a silicone cup.

4. Cupping therapy utilizes negative pressure to have a mechanical effect on treated tissues.

5. Traditional cupping therapy was a commonly used technique prior to the 20th century. During the turn of this century, trends indicate that there was a decline in use, possibly due to the advancement of medical research or the ambiguity of bloodletting procedures. However, this ancient practice has begun to re-emerge as a viable option for orthopedic injuries. This increase may be contributed to the 2016 Olympics or continued research in optimizing outcomes for athletes.

6. There is some evidence to suggest that cupping therapy can decrease musculoskeletal pain.

7. There is some evidence to suggest that cupping therapy can increase regional and local blood flow.

Table 4. Agreed Upon Prescription of Cupping Therapy1,2,5,13,15,22,29

\section{Indications}

1. Musculoskeletal pain is an indication for the use of cupping therapy.

2. Neurological pain is an indication for the use of cupping therapy provided direction is given by the patient's neurovascular specialist.

3. Muscle tightness is an indication for the use of cupping therapy.

4. Myofascial adhesions within a muscle are an indication for the use of cupping therapy.

5. Subacute and chronic muscular injuries are an indication for the use of cupping therapy.

\section{Contraindications}

1. Open wounds are a contraindication for the use of cupping therapy.

2. Pregnancy is a contraindication for cupping therapy over the lower back or torso.

3. Cupping therapy treatments on the appendages of pregnant patients should be done with caution, and when possible with physician consent.

4. Neurovascular compromise is a contraindication for the use of cupping therapy in the absence of referral by a neurovascular specialist.

5. Cupping therapy should not be performed on a muscle that has suffered an injury within the past 2472 hours.

Cupping therapy for athletic related injuries

1. There is a need for a larger number of high-quality studies on the use of cupping therapy in athletic training.

2. Several case studies have been published that suggest cupping therapy may be a viable treatment option for athletics related injuries.

3. In the absence of high-quality studies specific to athletics related injuries, clinicians and educators must rely on studies conducted on participants from the general population.

4. There is no time required for patients to refrain from participation in sport-related activities following use of cupping therapy, provided they complete an adequate dynamic warm up and are not experiencing soreness above patient tolerance. 
Table 5. Agreed Upon Considerations of Cupping Therapy ${ }^{1,4,5,12,15,29}$

\section{Application}

1. When treating a minor, it is necessary to educate the patient's parent or guardian and obtain consent from said guardian prior to performing cupping therapy.

2. Cupping therapy should be performed by or under the supervision of a properly educated healthcare professional.

3. Depending on the location, goal, and patient allergies, clinicians should use mediums such as coconut oil, grapeseed oil, and seedless massage oil to minimize patient discomfort during cupping therapy treatments.

4. An area with more body hair may require the use of more oil, but may still be more difficult to achieve suction on.

5. Therapeutic effects can be seen after as little as 10-minutes of treatment when using static cupping therapy depending on therapeutic goals.

6. Static cupping therapy can be performed safely for up to 30 -minutes depending on patient comfort and therapeutic goals.

7. When using plastic pump cups with patients who have not been cupped before, starting with 1 pump based on patient comfort is recommended.

8. Clinicians should use an amount of suction that does not elicit a painful response when treating patients who have not received cupping therapy treatments before.

9. Depending on therapeutic goals and patient tolerance, clinicians can generally use more suction when treating patients who have receive cupping therapy treatments before.

10. Clinicians can affect the amount of suction achieved during fire cupping by decreasing the amount of time from when the flame is removed from the cup and when the cup is placed on the intended treatment area.

11. Provided a patient's soreness has not increased and patients can tolerate the amount of suction, clinicians can utilize cupping therapy in the presence of muscular soreness.

\section{Reasons to Discontinue/Adverse effects}

1. If a patient expresses discomfort during cupping therapy, the clinician should discontinue treatment.

2. If blisters begin to form during cupping therapy, the clinician should discontinue treatment.

3. If blisters do form during cupping therapy, standard wound care treatment is appropriate provided there are no signs of infection.

4. If a patient begins to become lightheaded during cupping therapy, the clinician should discontinue treatment.

5. Presence of ecchymosis related to a previous cupping therapy treatment does not disqualify a patient from being treated with cupping therapy again provided the patient is not experiencing soreness.

\section{Following treatment}

1. Patients should be instructed to hydrate properly following cupping therapy.

2. Patients can reasonably expect to feel soreness similar to what would be expected after a deep tissue massage following cupping therapy.

Although the panel was able to reach consensus on the included statements, this study did have limitations. The literature review was designed to provide panelists with an overview of the most current literature. However, there was not a number of high-quality studies assessing the effects of cupping therapy. Additionally, the majority of these studies did not follow a standardized methodology that may have given the panel the opportunity to provide learner guidelines regarding the application of cupping therapy. Due to this limitation, the literature review was reviewed by a clinician with extensive experience with cupping therapy in order to ensure the literature review was completed in the most comprehensive and insightful way possible. Furthermore, the use of athletic trainers with their primary job setting as college/university may limit the generalizability to other job settings. Athletic trainers practicing in settings where the majority of their patients are minors may have additional considerations they need to make. Future research should incorporate panelists from other athletic training settings to increase the generalizability of 
these statements. A final limitation that is that the Delphi technique has been suggested to not meet the same standards as other scientific methods. 6 That being said, the controlled feedback and clinician input that is characteristic of this technique is ideally suited for creation of a consensus statement on a treatment technique that currently has gaps and contradictions within the available literature.

\section{CONCLUSIONS}

The remaining 39 statements provide an expert statement on the definition and description, prescription, and application of cupping therapy for athletic training clinical practice. This cliniciandriven expert statement using the Delphi technique provides a framework for safe and effective cupping therapy practices based off of best available evidence and clinician expertise. This statement is presented with the intent of providing direction for decision making regarding the prescription and application of cupping therapy.

\section{THE CUPPING THERAPY PANEL OF EXPERTS}

The authors would like to thank: Travis Armstrong, MS, LAT, ATC (Arizona Christian University, Glendale, AZ), Alifonzo Garcia, MS, LAT, ATC (Arizona Christian University, Glendale, AZ), Kerri Kalina, MS, LAT, ATC (University of Texas at Dallas, Richardson, TX), Tracy Lott, MS, LAT, ATC (Texas A\&M University Commerce, Commerce, TX) Nicole Murzen, MS, ATC (Soka University of America, Aliso Viejo, CA), Tyler Rediger, LAT, ATC (University of Texas at Tyler, Tyler, TX), J.J. Sayson, MAT, LAT, ATC (Grand Canyon University, Phoenix, AZ), and Sarah Wambheim, MAT, ATC (University of Minnesota, Minneapolis, MN) for their participation in the panel.

Copyright ( Indiana State University ISSN Online 2577-8188

\section{REFERENCES}

1. Bridgett $R$, Mas $D$, Prac $C$, Klose $P$, Duffield $R$, Mydock S, Lauche R. Effects of cupping therapy in amateur and professional athletes: Systematic review of randomized controlled trials. J Altern Complement Med. 2018; 24(3): 208-219. https://doi.org/10.1089/acm.2017.0191

2. Futterman M. Michael Phelps leads Rio cupping craze. The Wall Street Journal. August 8, 2016.

https://www.wsj.com/articles/michaelphelps-leads-the-rio-cupping-craze1470687866

3. Lyons K. Interest in cupping therapy spikes after Michael Phelps gold win. The Guardian. August 9, 2016. https://www.theguardian.com/sport/2016 Laug/08/cupping-therapy-interest-spikesmichael-phelps-rio-olympics

4. Cao H, Li X, Yan X, Wang N, Bensoussan A, Liu J. Cupping therapy for acute and chronic pain management: A systematic review. J Tradit Chin Med. 201 4; 2: 49-61. https://doi.org/10.1016/i.jtcms.2014.11.0 $\underline{03}$

5. Cao H, Li X, Liu J. An updated review of the efficacy of cupping therapy. PLos ONE. 2012 ; $7(2)$. https://doi.org/10.1371/journal.pone.003 $\underline{1793}$

6. Maher T, Whyte $M$, Hoyles R, Parfrey $H$, Ochiai $Y$, Mathieson N, Turnbull A, Williamson N, Bennett B. Development of a consensus statement for the definition, diagnosis, and treatment of acute exacerbations of idiopathic pulmonary fibrosis using the Delphi technique. Adv Ther. 2015;32:929-943.

https://dx.doi.org/10.1007\%2Fs 1 2325015-0249-6

7. Ilic D, Nordin R, Glasziou P, Tilson J, Viallnueva E. Development and validation of the ACE tool: Assessing medical trainees' competency in evidence based medicine. BMC Med Educ. 2014;14(1):114. https://doi.org/10.1186/1472-6920-14$\underline{114}$

8. Rosier P, De Ridder D, Meijlink J, Webb R, Whitmore K, Drake M. Developing evidence-based standards for diagnosis and management of lower urinary tract or 
pelvic floor dysfunction. Neurouro Urodyn. $2012 ; 31(5): 621-4$. https://doi.org/10.1002/nau.21253

9. Dimitrow $M$, Airaksinen $M$, Kivela $S$, Lyles $A$, Leikola S. Comparison of prescribing criteria to evaluate the appropriateness of drug treatment in individuals aged 65 and older: A systematic review. J Am Geriatr Soc. $2011 ; 59(8): 1521-30$.

https://doi.org/10.1111/i.15325415.2011.03497.x

10. Aboushanab TS \& AlSanad, S. Cupping therapy: An overview from modern medicine perspective. J Acupunct Meridian Stud. $2018 ; 11$ (3):83-87. https://doi.org/10.1016/i.jams.2018.02.0 01

11. Ahanger AA, Prawez $S$, Leo MD, Kathirvel K, Kumar D, Tandan SK, Malik JK. Prohealing potential of hemin: An inducer of heme oxygenase-1. Eur J Pharmacol. 2010; 645(1-3):165-170.

https://doi.org/10.1016/i.eiphar.2010.06. $\underline{048}$

12. Arce-Esquivel AA, Warner BJ, Gallegos DM, Cage SA. Effect of dry cupping on vascular function among young individuals. Int J Health Sci. 2017;5(3):10-15. https://doi.org/10.15640/ijhs.v5n3a2

13. Barger KM, Warren AJ, Volberding JL, O'Brien MS, DeFreitas JM. Compressive versus decompressive soft tissue therapy on acute hamstring flexibility and pain in male athletes with perceived hamstring tightness. J Athl Train. 2017;52(6S):S-94. https://doi.org/10.4085/1062-605052.6.5 1

14. Biehl MM, Selkow NM, Begalle RL. The therapeutic effects of dry cupping on iliotibial band tightness. J Athl Train. 2018;53(6S):S-152-153. https://doi.org/10.4085/1062-605053.6s.s 1

15. Cage SA, Gallegos DM, Warner BJ. Utilization of cupping therapy in the treatment of vascular thoracic outlet syndrome in a collegiate pitcher: A case study. JSMAHS. 2017;3(2). https://doi.org/10.25035/ismahs.03.02.02

16. Chen B, Guo Y, Li MY, Chen ZL, Guo Y. Standardization of cupping therapy may reduce adverse effects. QJM-Int J Med. $2016 ; 4(1) 287$. https://doi.org/10.1093/qimed/hcv220
17. Chi LM, Lin LM, Chen CL, Wang SF, Lai HL, Peng TC. The effectiveness of cupping therapy on relieving chronic neck and shoulder pain: A randomized controlled trial. Evid Based Complement and Alternat Med. 2016. https://doi.org/10.1155/2016/7358918

18. Denegar CR, Saliba E, Saliba S. Therapeutic Modalities for Musculoskeletal Injuries. Champaign, IL: Human Kinetics. 2017.

19. Emerich $M$, Braeunig $M$, Clement HW, Ludtke R, Huber R. Mode of action of cupping - Local metabolism and pain thresholds in neck pain patients and healthy subjects. Complement Ther Med.

2014;22(1):148-158. https://doi.org/10.1016/i.ctim.2013.12.01 $\underline{3}$

20. Ernst E. Testing traditional cupping therapy. J Pain. 2009; 1 0(6):555. https://doi.org/10.1016/i.jpain.2009.02.0 $\underline{01}$

21. Escaloni J, Young I, Loss, J. Cupping with neural glides for the management of peripheral neuropathic pain: A case study. J Man Manip Ther. 2019;27(1):54-61. https://doi.org/10.1080/10669817.2018. 1514355

22. Fiesler T, Warner BJ, Berry VA, Mesman DL, Cage SA. Low back pain as a complication of slipped capital femoral epiphysis in a collegiate volleyball player. J Athl Train. $53(6 S)$, S-322.

https://doi.org/10.4085/1062-605053.6s.s1

23. Gozubuyu OB, Devran S, Akikol M. The effects of dry cupping therapy on muscle thickness and elasticity of upper back muscles. J Body Move Ther. 2018;22(4):851. http://dx.doi.org/10.1016/i.jbmt.2018.09. $\underline{018}$

24. Kouskoukis CE, Leider M. Cupping: The art and the value. Am J Dermatopathol. 1993;5(3):235-239.

25. Lee SY, Sin Jl, Yoo HK, Kim TS, Sung KY. Cutaneous myobacterium massiliense infection associated with cupping therapy. Clin Exp Dermtol. 2014;39:904-907. https://doi.org/10.1111/ced.12431

26. Lin CW, Wang JT, Choy CS, Tung HH. latrogenic bullae following cupping therapy. J Altern Complemt Med. 2009; 15(1 1):1243-1245. https://doi.org/10.1089/acm.2009.0282 
27. Liu Z, Chen C, Li X, Zhao C, Li Z, Liang W, Lin $Y$. Is cupping blister harmful? - A proteomical analysis of blister fluid induced by cupping therapy and scald. Complement Ther Med. 2018;36:25-29.

https://doi.org/10.1016/i.ctim.2017.11.00 $\underline{2}$

28. Liu W, Piao S, Meng X, Wei LH. Effects of cupping on blood flow under the skin of back in healthy human. World $J$ Acupint Moxibustion. 2013;23(3):50-52. https://doi.org/10.1016/S10035257(13)60061-6

29. Lowe DT. Cupping therapy: An analysis of the effects of suction on skin and the possible influence on human health. Complemet Ther Clin Pract. 2017;29:162168. https://doi.org/10.1016/i.ctcp.2017.09.0 $\underline{08}$

30. Lu MC, Yang CJ, Tsai SH, Hung CC, Chen SJ. Intraperitoneal hemorrhage after cupping therapy. J Emerg Med. 2018;1-3. https://doi.org/10.1177/102490791878 $\underline{4076}$

31. McNulty E, Thompson T, McKeon JM. Dry cupping with motion is effective for achieving small gains in hamstring flexibility in healthy adults. J Athl Train.

$2018 ; 53(6 S): S-152$.

https://doi.org/10.4085/1062-605053.6s.s 1

32. Mohammadi S, Roostayi MM, Naimi SS, Baghban AA. The effects of cupping therapy as a new approach in the physiotherapeutic management of carpal tunnel syndrome. Phsyiother Res In. $201 ; \mathrm{e} 1170$. https://doi.org/10.1002/pri.1770

33. Parapia LA. History of bloodletting by phlebotomy. B J Haematol. 2008; 143(4):490-495. https://doi.org/10.1111/i.13652141.2008.07361.x

34. Potter NB, Wilson, JC. Internal Medicine: A Work for the Practicing Physician on Diagnosis and Treatment with a Complete Desk Index. Philadelphia, PA: J.B. Lippincott Company. 1919.

35. Valmyre A. Cupping. BJM.

1924;1 (3295):351-352. 